\title{
The Research on the Appraisal of Market Opportunity Based on AHP
}

\author{
Donghong YANG ${ }^{1}$, Yujie TAN ${ }^{1}$, Yanbin SUN ${ }^{1}$ \\ ${ }^{1}$ School of Economics and Management, Daqing Petroleum Institute, Daqing, China. \\ Email: dqyangdonghong@126.com
}

Received April 21, 2009; revised June 25, 2009; accepted August 2, 2009.

\begin{abstract}
In this article, through analyzing the inner and external environments of the manufacture enterprise, the hierarchy model of the market opportunity has been constructed. Based on the AHP, the mathematics evaluation model of the market opportunity has been established. Take a simulative enterprise as example, according to the hierarchy model and the mathematics evaluation model of the market opportunity, the judgment matrixes of every hierarchy have been established and the weight of each market opportunity opposite to the target hierarchy is obtained. The reasonable decision-making method has been provided to choose the market opportunity for the manufacture enterprise.
\end{abstract}

Keywords: Analysis Hierarchy Process, Market Opportunity, Environment Analysis

\section{Introduction}

With the change and development of the market demand and the intense competition environment in the market, any manufacture enterprise can not always rely on the existing products and services. If the manufacture enterprise wants to survive and develop for a long time, it must look for new market opportunities.

In the internal and external enterprise environment, market opportunities are situation and opportunities which can make the manufacture enterprise get tremendous benefit and develop rapidly. Market opportunities existing in the internal and external environment are the customer demand which have not yet been met or fully met [1].

Market opportunities generally exist in two situations. First, to find the new or potential customers for the existing products and services and to start and develop a new market, or to find the new features and new uses of existing products and guide people to use them. Second, to create, develop, design and produce new products or new services which have new features to meet the changing needs of people.

Along with the changes of market environment, demand also will be changed. Therefore, market opportunities will emerge or disappear. Any market opportunity objectively exists and any enterprise can find and take advantage of the market opportunities. There are no exclusive rights [2].

However, just in the specific conditions one market opportunity can success. Because of the different condi- tions of the manufacture enterprises, in the use of a market opportunity, the different manufacture enterprises will gain different interests and competitive advantages. Therefore, manufacture enterprises must accurately analyze and evaluate the market opportunities to find one that is suitable for the manufacture enterprise's development.

\section{The Appraisal of Market Opportunity}

\subsection{The Appraisal Process of Market Opportunity}

Market opportunities come from customer demand, and customer demand changes with the internal and external environment of the manufacture enterprise. When looking for market opportunities, the manufacture enterprises analyze the enterprise's suppliers, customers and competitors, as well as the internal organizational structure, financial status, professional skills, human resources and network conditions [3]. The optimal market opportunity can be identified after analysis and evaluation. (See Figure 1)

\subsection{The Hierarchy Model of Market Opportunity}

The market gravitation, the enterprise resource, the competitors and the customers are considered to analyze and evaluate a particular market opportunity or some market opportunities which is whether conform to manufacture enterprise development needs or not. 


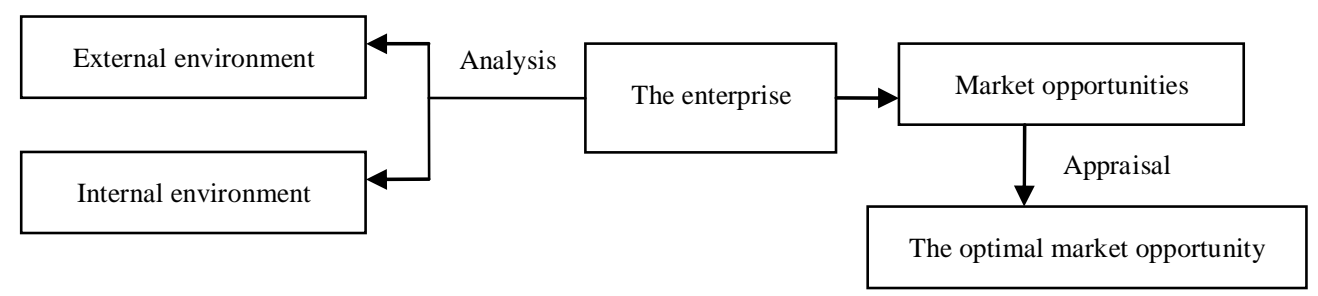

Figure 1. The appraisal process of market opportunity

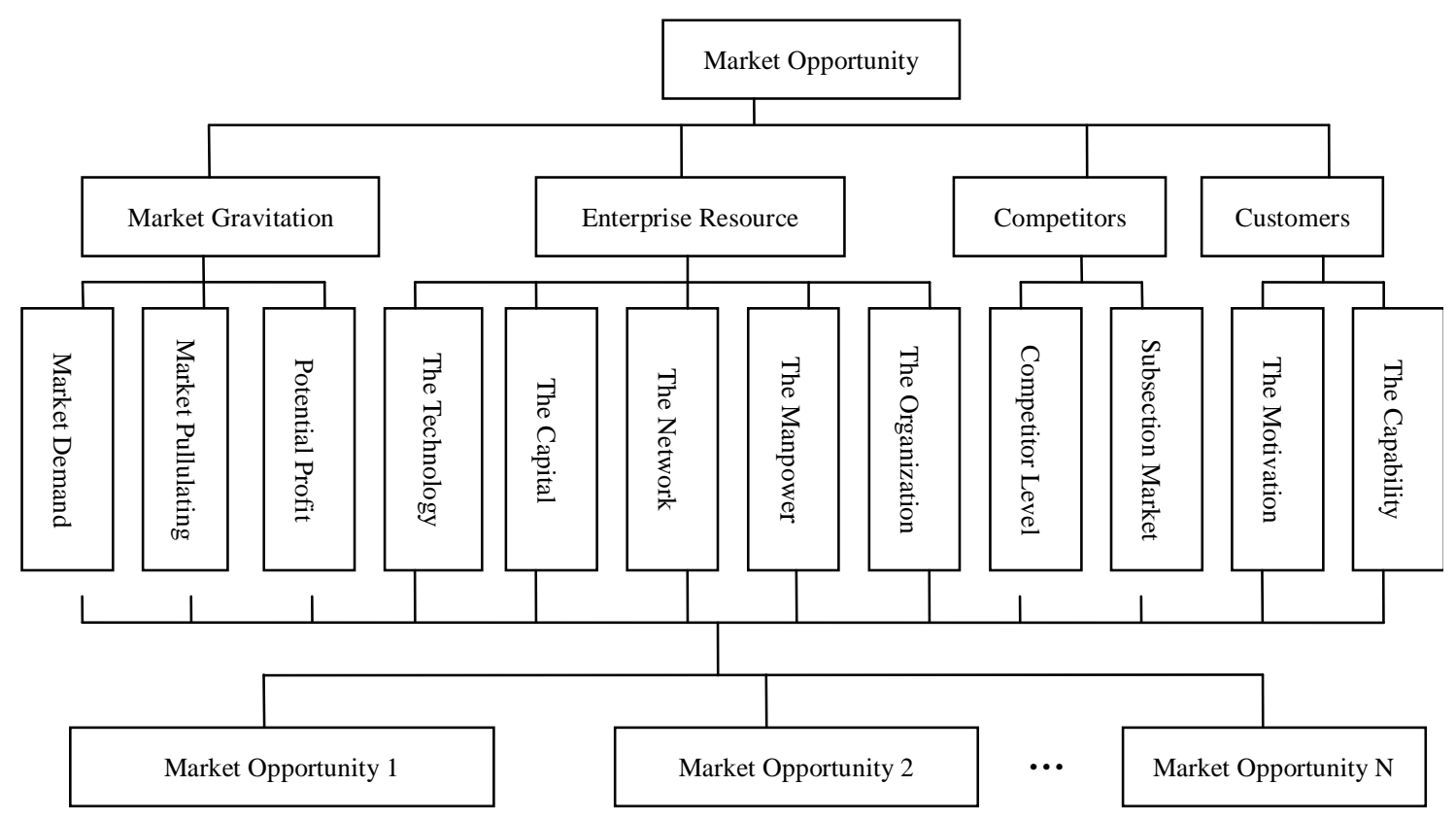

Figure 2. The hierarchy model of the market opportunity

The market gravitation refers to market attract ability to specific products which are produced by the enterprise. The market gravitation includes market demand, market pullulatin and potential profit. The more the market demand of products and services, the market more attract the products and services of enterprise. The market profitability of products and services is high, the capital profitability is high, which attracts enterprises to product the products and services.

The enterprise resource is the useful thing which is worth for the survival and development of enterprise. The enterprise resource is an important foundation conditions for production and operation of enterprise. The enterprise resources include the technology, the capital, the network, the manpower and the organization. When the market can effectively and rationally use resources of enterprise, in accordance with the advantages of enterprise resources into products and management, and get benefit through sale, the market opportunity is fit for the survival and development of enterprise.

In a certain degree of market competition environment, when the enterprises analyze and evaluate the market opportunities, the competitor level and subsection market should be considered.

The products and services will be sold to the customers. So when the enterprises analyze and evaluate the market opportunities, the consumption motivation and the consumption capability should be considered.

The hierarchy model of the market opportunity is established as follow. (See Figure 2)

\subsection{The Mathematics Evaluation Model of Market Opportunity}

\subsubsection{Constructing Judgment Matrixes}

Through paired comparing the factors, the judgment matrix $A=\left(a_{i j}\right)_{n \times n}$ is constructed. In determining the value of $a_{i j}$, the 1-9 and their reciprocals are quoted [4].

\subsubsection{Single-Level Ranking and Consistency Test}

1) Single-level ranking

The eigenvector $W$ normalized corresponding to the judgment matrix is the Sort weights of the factors corresponding to the factor on the above hierarchy. When 
calculating the maximum eigenvalue $\lambda_{\max }$ and $W$, the method is as follows [5].

(a) Each list of matrix elements is standardized. The general element is

$$
\bar{a}_{i j}=\frac{a_{i j}}{\sum_{k=1}^{n} a_{k j}} \quad(i, j=1,2, \cdots, n)
$$

(b) The summation of elements in each row of the judgment matrix standardized is gained.

$$
\bar{W}_{i}=\sum_{j=1}^{n} \bar{a}_{i j} \quad(i=1,2, \cdots, n)
$$

(c) The vector $\bar{W}=\left(\bar{W}_{1}, \bar{W}_{2}, \cdots, \bar{W}_{n}\right)^{T}$ is standardized.

$$
W_{i}=\frac{\bar{W}_{i}}{\sum_{i=1}^{n} \bar{W}_{i}}(i=1,2, \cdots, n)
$$

The vector $W=\left(W_{1}, W_{2}, W_{3}, \cdots, W_{n}\right)^{T}$ is the Single-level sort weights, and the maximum eigenvalue is

$$
\lambda_{\max }=\sum_{i=1}^{n} \frac{(A W)_{i}}{n W_{i}}
$$

2) Consistency test

(a) The consistency target is

$$
C I=\frac{\lambda_{\max }-n}{n-1}
$$

(b) Find the corresponding average random consistency target $R I$ which is shown in Table 1.

(c) The consistency proportion is

$$
C R=\frac{C I}{R I}
$$

When $C R<0.10$, the consistency of judgment matrix is acceptable, otherwise, the judgment matrix is modified, and then its consistency is tested.

\subsubsection{Sort of Level Ranking and Consistency Test}

1) Sort of level ranking

The hierarchical model includes target layer $A$, guideline $B$ and project $C$. The relative weights of target layer $A$ corresponding to guidelines $B$ is $W^{(1)}=$ $\left(W_{1}^{(1)}, W_{2}^{(1)}, W_{3}^{(1)}, \cdots, W_{k}^{(1)}\right)^{T}$

The relative weights of the various criteria of guideline $B$ corresponding to project $C$ is $W_{j}^{(2)}=\left(W_{1 j}^{(2)}, W_{2 j}^{(2)}\right.$, $\left.W_{3 j}^{(2)}, \cdots, W_{n j}^{(2)}\right)^{T}(j=1,2, \cdots, k)$.

The relative weights of projects corresponding to target layer $A$ is calculated in the Table 2 .

2) Consistency test

$$
C R=\frac{\sum_{j=1}^{m} C I_{j} a_{j}}{\sum_{j=1}^{m} R I_{j} a_{j}}
$$

When $C R<0.10$, the consistency of judgment matrix is acceptable, otherwise, the judgment matrix is modified, and then its consistency is tested.

The vector $W=\left(W_{1}, W_{2}, W_{3}, \cdots, W_{n}\right)^{T}$ is the relative weights of the projects. The policy-makers choose the project whose weight is the greatest as the optimal project.

\section{Empirical Analysis}

The market opportunities are identified by application of the model. The simulative manufacture enterprise is now facing three chances to choose, to be known as A, B and

Table 1. The average random consistency target of judgment matrix ${ }^{[6]}$

\begin{tabular}{c|rrrrrrrrr}
\hline Rank & 1 & 2 & 3 & 4 & 5 & 6 & 7 & 8 & 9 \\
RI & 0.00 & 0.00 & 0.58 & 0.90 & 1.12 & 1.24 & 1.32 & 1.41 & 1.45 \\
\hline
\end{tabular}

Table 2. Sort of level ranking

\begin{tabular}{cc|cccc|c}
\hline \multirow{2}{*}{ H.C } & H. B & B1 & B2 & $\ldots$ & Bk & Sort of level Ranking \\
& & $\mathrm{W} 1$ & $\mathrm{~W} 2$ & $\ldots$ & $\mathrm{Wk}$ & \\
\hline & $\mathrm{W} 11$ & $\mathrm{~W} 12$ & $\ldots$ & $\mathrm{W} 1 \mathrm{k}$ & \\
$\mathrm{C} 1$ & $\mathrm{~W}_{21}$ & $\mathrm{~W}_{22}$ & $\ldots$ & $\mathrm{W}_{2 \mathrm{k}}$ & $W_{i}=\sum_{j=}^{k} W_{j}^{(1)} * W_{i j}^{(2)}$ \\
$\mathrm{C} 2$ & $\vdots$ & $\vdots$ & & $\vdots$ & $(i=1,2, \cdots n)$ \\
$\mathrm{Cn}$ & $\mathrm{W}_{\mathrm{n} 1}$ & $\mathrm{~W}_{\mathrm{n} 2}$ & $\ldots$ & $\mathrm{W}_{\mathrm{nk}}$ & \\
\hline
\end{tabular}


C. The basic steps of identifying and evaluating the market opportunities are as follows.

First, the hierarchy model of the market opportunity is drawn. (See Figure 2)

Then, the judgment matrixes are constructed. (See Table 3 to Table 19)

Table 3. The judgment matrix of A-B

\begin{tabular}{cccccc}
\hline $\mathrm{A}$ & $\mathrm{B}_{1}$ & $\mathrm{~B}_{2}$ & $\mathrm{~B}_{3}$ & $\mathrm{~B}_{4}$ & $\mathrm{~W}$ \\
\hline $\mathrm{B}_{1}$ & 1 & $1 / 3$ & 3 & 2 & 0.246 \\
$\mathrm{~B}_{2}$ & 3 & 1 & 4 & 3 & 0.497 \\
$\mathrm{~B}_{3}$ & $1 / 3$ & $1 / 4$ & 1 & 2 & 0.142 \\
$\mathrm{~B}_{4}$ & $1 / 2$ & $1 / 3$ & $1 / 2$ & 1 & 0.115 \\
\hline
\end{tabular}

$\lambda_{\text {max }}=\sum_{i=1}^{n} \frac{(A W) i}{n W i}=4.215, \quad C I=\frac{\lambda_{\max }-n}{n-1}=0.072, \quad C R=\frac{C I}{R I}=0.080<$ 0.1 , the consistency is satisfactory.

Table 4. The judgment matrix of $\mathrm{B}_{1}-\mathrm{C}$

\begin{tabular}{ccccc}
\hline$B_{1}$ & $C_{11}$ & $C_{12}$ & $C_{13}$ & $W$ \\
\hline$C_{11}$ & 1 & $1 / 3$ & $1 / 4$ & 0.120 \\
$C_{12}$ & 3 & 1 & $1 / 3$ & 0.272 \\
$C_{13}$ & 4 & 3 & 1 & 0.608 \\
\hline
\end{tabular}

$\lambda_{\text {max }}=3.074, C I=0.037, C R=0.064<0.1$, the consistency is satisfactory.

Table 5. The judgment matrix of $\mathrm{B}_{2}-\mathrm{C}$

\begin{tabular}{ccccccr}
\hline$B_{2}$ & $C_{21}$ & $C_{22}$ & $C_{23}$ & $C_{24}$ & $C_{25}$ & $W$ \\
\hline$C_{21}$ & 1 & $1 / 2$ & 3 & 4 & 5 & 0.301 \\
$C_{22}$ & 2 & 1 & 3 & 4 & 5 & 0.397 \\
$C_{23}$ & $1 / 3$ & $1 / 3$ & 1 & 3 & 2 & 0.146 \\
$C_{24}$ & $1 / 4$ & $1 / 4$ & $1 / 3$ & 1 & 3 & 0.097 \\
$C_{25}$ & $1 / 5$ & $1 / 5$ & $1 / 2$ & $1 / 3$ & 1 & 0.059 \\
\hline
\end{tabular}

$\lambda_{\max }=5.280, \quad C I=0.070, \quad C R=0.062<0.1$, the consistency is satisfactory.

Table 6. The judgment matrix of $\mathrm{B}_{3}-\mathrm{C}$

\begin{tabular}{cccc}
\hline$B_{3}$ & $C_{31}$ & $C_{32}$ & $W$ \\
\hline$C_{31}$ & 1 & $1 / 2$ & 0.333 \\
$C_{32}$ & 2 & 1 & 0.667 \\
\hline
\end{tabular}

$\lambda_{\max }=2, \quad C I=0, \quad C R=0<0.1$, the consistency is satisfactory.

Table 7. The judgment matrix of $\mathrm{B}_{4}-\mathrm{C}$

\begin{tabular}{rlcr}
\hline$B_{4}$ & $C_{41}$ & $C_{42}$ & $W$ \\
$C_{41}$ & 1 & $1 / 3$ & 0.250 \\
$C_{42}$ & 3 & 1 & 0.750 \\
\hline
\end{tabular}

$\lambda_{\max }=2, C I=0, C R=0<0.1$, the consistency is satisfactory.
Table 8. The judgment matrix of $\mathrm{C}_{11}-\mathrm{D}$

\begin{tabular}{ccccc}
\hline$C_{11}$ & $D_{1}$ & $D_{2}$ & $D_{3}$ & $W$ \\
\hline$D_{1}$ & 1 & 2 & 3 & 0.539 \\
$D_{2}$ & $1 / 2$ & 1 & 2 & 0.297 \\
$D_{3}$ & $1 / 3$ & $1 / 2$ & 1 & 0.164 \\
\hline
\end{tabular}

$\lambda_{\max }=3.009, \quad C I=0.005, \quad C R=0.008<0.1$, the consistency is satisfactory.

Table 9. The judgment matrix of $\mathrm{C}_{12}-\mathrm{D}$

\begin{tabular}{ccccc}
\hline$C_{12}$ & $D_{1}$ & $D_{2}$ & $D_{3}$ & $W$ \\
\hline$D_{1}$ & 1 & $1 / 3$ & $1 / 4$ & 0.123 \\
$D_{2}$ & 3 & 1 & $1 / 2$ & 0.320 \\
$D_{3}$ & 4 & 2 & 1 & 0.557 \\
\hline
\end{tabular}

$\lambda_{\max }=3.018, \quad C I=0.009, \quad C R=0.016<0.1$, the consistency is satisfactory.

Table 10.The judgment matrix of $\mathrm{C}_{13}-\mathrm{D}$

\begin{tabular}{ccccr}
\hline$C_{13}$ & $D_{1}$ & $D_{2}$ & $D_{3}$ & $W$ \\
\hline$D_{1}$ & 1 & $1 / 3$ & $1 / 3$ & 0.141 \\
$D_{2}$ & 3 & 1 & 2 & 0.525 \\
$D_{3}$ & 3 & $1 / 2$ & 1 & 0.334 \\
\hline
\end{tabular}

$\lambda_{\max }=3.054, C I=0.027, C R=0.046<0.1$, the consistency is satisfactory.

Table 11.The judgment matrix of $\mathrm{C}_{21}-\mathrm{D}$

\begin{tabular}{ccccc}
\hline$C_{21}$ & $D_{1}$ & $D_{2}$ & $D_{3}$ & $W$ \\
\hline$D_{1}$ & 1 & $1 / 3$ & $1 / 2$ & 0.164 \\
$D_{2}$ & 3 & 1 & 2 & 0.539 \\
$D_{3}$ & 2 & $1 / 2$ & 1 & 0.297 \\
\hline
\end{tabular}

$\lambda_{\max }=3.009, \quad C I=0.005, \quad C R=0.008<0.1$, the consistency is satisfactory.

Table 12. The judgment matrix of $C_{22}-D$

\begin{tabular}{ccccc}
\hline$C_{22}$ & $D_{1}$ & $D_{2}$ & $D_{3}$ & $W$ \\
\hline$D_{1}$ & 1 & $1 / 4$ & $1 / 3$ & 0.120 \\
$D_{2}$ & 4 & 1 & 3. & 0.608 \\
$D_{3}$ & 3 & $1 / 3$ & 1 & 0.272 \\
\hline
\end{tabular}

$\lambda_{\max }=3.074, C I=0.037, \quad C R=0.064<0.1$, the consistency is satisfactory.

Table 13. The judgment matrix of $C_{23}-D$

\begin{tabular}{ccclr}
\hline$C_{23}$ & $D_{1}$ & $D_{2}$ & $D_{3}$ & $W$ \\
\hline$D_{1}$ & 1 & $1 / 3$ & 2 & 0.252 \\
$D_{2}$ & 3 & 1 & 3 & 0.589 \\
$D_{3}$ & $1 / 2$ & $1 / 3$ & 1 & 0.159 \\
\hline
\end{tabular}

$\lambda_{\max }=3.054, C I=0.027, C R=0.046<0.1$, the consistency is satisfactory. 
Table 14. The judgment matrix of $\mathrm{C}_{24}-\mathrm{D}$

\begin{tabular}{ccccc}
\hline$C_{24}$ & $D_{1}$ & $D_{2}$ & $D_{3}$ & $W$ \\
\hline$D_{1}$ & 1 & 3 & 2 & 0.525 \\
$D_{2}$ & $1 / 3$ & 1 & $1 / 3$ & 0.142 \\
$D_{3}$ & $1 / 2$ & 3 & 1 & 0.334 \\
\hline
\end{tabular}

$\lambda_{\text {max }}=3.054, C I=0.027, \quad C R=0.046<0.1$, the consistency is satisfactory.

Table 15. The judgment matrix of $\mathrm{C}_{25}-\mathrm{D}$

\begin{tabular}{ccccc}
\hline$C_{25}$ & $D_{1}$ & $D_{2}$ & $D_{3}$ & $W$ \\
\hline$D_{1}$ & 1 & $1 / 3$ & $1 / 2$ & 0.159 \\
$D_{2}$ & 3 & 1 & 3 & 0.589 \\
$D_{3}$ & 2 & $1 / 3$ & 1 & 0.252 \\
\hline
\end{tabular}

$\lambda_{\max }=3.054, \quad C I=0.027, \quad C R=0.046<0.1$, the consistency is satisfactory.

Table 16. The judgment matrix of $\mathrm{C}_{31}-\mathrm{D}$

\begin{tabular}{ccccc}
\hline$C_{31}$ & $D_{1}$ & $D_{2}$ & $D_{3}$ & $W$ \\
\hline$D_{1}$ & 1 & $1 / 5$ & $1 / 3$ & 0.106 \\
$D_{2}$ & 5 & 1 & 3 & 0.633 \\
$D_{3}$ & 3 & $1 / 3$ & 1 & 0.261 \\
\hline
\end{tabular}

$\lambda_{\text {max }}=3.039, \quad C I=0.019, \quad C R=0.033<0.1$, the consistency is satisfactory.
Table 17. The judgment matrix of $\mathrm{C}_{32}-\mathrm{D}$

\begin{tabular}{ccccc}
\hline$C_{32}$ & $D_{1}$ & $D_{2}$ & $D_{3}$ & $W$ \\
\hline$D_{1}$ & 1 & 4 & 3 & 0.620 \\
$D_{2}$ & $1 / 4$ & 1 & 2 & 0.224 \\
$D_{3}$ & $1 / 3$ & $1 / 2$ & 1 & 0.156 \\
\hline
\end{tabular}

$\lambda_{\max }=3.109, \quad C I=0.055, \quad C R=0.094<0.1$, the consistency is satisfactory.

Table 18. The judgment matrix of $\mathrm{C}_{41}-\mathrm{D}$

\begin{tabular}{ccccc}
\hline$C_{41}$ & $D_{1}$ & $D_{2}$ & $D_{3}$ & $W$ \\
\hline$D_{1}$ & 1 & 4 & 5 & 0.665 \\
$D_{2}$ & $1 / 4$ & 1 & 3 & 0.231 \\
$D_{3}$ & $1 / 5$ & $1 / 3$ & 1 & 0.104 \\
\hline
\end{tabular}

$\lambda_{\max }=3.087, \quad C I=0.043, \quad C R=0.075<0.1$, the consistency is satisfactory.

Table 19. The judgment matrix of $\mathrm{C}_{42}-\mathrm{D}$

\begin{tabular}{ccccc}
\hline$C_{42}$ & $D_{1}$ & $D_{2}$ & $D_{3}$ & $W$ \\
\hline$D_{1}$ & 1 & 4 & 3 & 0.620 \\
$D_{2}$ & $1 / 4$ & 1 & 2 & 0.224 \\
$D_{3}$ & $1 / 3$ & $1 / 2$ & 1 & 0.156 \\
\hline
\end{tabular}

$\lambda_{\max }=3.109, \quad C I=0.055, \quad C R=0.094<0.1$, the consistency is satisfactory.

Table 20. Sort of level ranking

\begin{tabular}{|c|c|c|c|c|c|c|c|c|c|c|c|c|c|}
\hline \multirow{3}{*}{$\begin{array}{l}\text { H. B } \\
\text { H. D }\end{array}$} & \multirow{2}{*}{\multicolumn{3}{|c|}{$\frac{\text { B1 }}{0.246}$}} & \multirow{2}{*}{\multicolumn{5}{|c|}{$\frac{\text { B2 }}{0.497}$}} & \multirow{2}{*}{\multicolumn{2}{|c|}{$\begin{array}{c}\text { B3 } \\
0.142\end{array}$}} & \multirow{2}{*}{\multicolumn{2}{|c|}{$\begin{array}{c}\text { B4 } \\
0.115\end{array}$}} & \multirow{3}{*}{ W } \\
\hline & & & & & & & & & & & & & \\
\hline & $\begin{array}{c}\mathrm{C}_{11} \\
0.120\end{array}$ & $\begin{array}{c}\mathrm{C}_{12} \\
0.272\end{array}$ & $\begin{array}{c}\mathrm{C}_{13} \\
0.608\end{array}$ & $\begin{array}{c}\mathrm{C}_{21} \\
0.301\end{array}$ & $\begin{array}{c}\mathrm{C}_{22} \\
0.397\end{array}$ & $\begin{array}{c}\mathrm{C}_{23} \\
0.146\end{array}$ & $\begin{array}{c}\mathrm{C}_{24} \\
0.097\end{array}$ & $\begin{array}{c}\mathrm{C}_{25} \\
0.059\end{array}$ & $\begin{array}{c}\mathrm{C}_{31} \\
0.333\end{array}$ & $\begin{array}{c}\mathrm{C}_{32} \\
0.667\end{array}$ & \multirow{2}{*}{$\begin{array}{c}\mathrm{C}_{41} \\
0.250 \\
\\
\end{array}$} & $\begin{array}{c}\mathrm{C}_{42} \\
0.750\end{array}$ & \\
\hline $\mathrm{D}_{1}$ & 0.539 & 0.123 & 0.141 & 0.164 & 0.120 & 0.252 & 0.525 & 0.159 & 0.106 & 0.620 & & 0.620 & 0.278 \\
\hline $\mathrm{D}_{2}$ & 0.297 & 0.320 & 0.525 & 0.539 & 0.608 & 0.589 & 0.142 & 0.589 & 0.633 & 0.224 & 0.231 & 0.224 & 0.453 \\
\hline $\mathrm{D}_{3}$ & 0.164 & 0.557 & 0.334 & 0.297 & 0.272 & 0.159 & 0.334 & 0.252 & 0.261 & 0.156 & 0.104 & 0.156 & 0.269 \\
\hline
\end{tabular}

The single-level ranking is done. The consistency of all the judgment matrixes is satisfactory. (See Table 20)

The relative weights of projects corresponding to target layer $A$ is calculated in the Table 6 . The corresponding average random consistency proportion of hierarchy $\mathrm{B}$ is $C R=0.063<0.10$, the consistency is satisfactory.

According to the comprehensive analysis of market opportunities, the ranking of the three market opportunities is Market Opportunity2, Market Opportunity1, Market Opportunity3.

\section{The Significance of Market Opportunity Evaluation}

Through analyzing and evaluating market opportunities, the manufacture enterprise can expand reproduction to promote the enterprise to a higher stage. The manufacture enterprise can maintain the normal production and operation, but also can seeks to growth and progress.

The survival and development of manufacture enterprises can not be separated from environment. From the macro-environment, the survival and development of 
manufacture enterprises is restricted mainly by the changes of the demographic, economic, political and legal, scientific and technological, natural, social and cultural environment. From the micro-environment, the survival and development of manufacture enterprises is closely influenced and affected by their own internal factors, place affiliated companies, customers, competitors, the public and so on. To adapt to the environment is the most basic issues of manufacture enterprises survival. Only concerning any change from the environment at any time, finding out the problems timely, evaluating the favorable market opportunities timely and avoiding the risk, the manufacture enterprise can get better living space to enhance the capacity of adapt to the environment.

The development assurances can not be separable from the relatively stable profits and revenue. Through continuously analyzing and evaluating market opportunities, the manufacture enterprise can excavate new growth point to demand the products which can fully meet needs and desires for market. Combined with reasonable prices, convenient place and appropriate promotion, the manufacture enterprise will be able to expand revenues, en- hance its effectiveness, so as to stabilize the profitability of manufacture enterprises.

\section{REFERENCES}

[1] L. Q. Meng, "Distinguishing and evaluating market opportunity of enterprise,” Journal of Lianyungang College of Chemical Technology, Vol. 3, No. 2, pp. 57, 1997.

[2] J. C. Li, "The study and analysis of national market chance of printing enterprise,” Wuhan University, China, 2005.

[3] J. Gao and M. Zhang, "Marketing skill for enterprise to recognize market opportunities,” Northern Economy and Trade, Vol. 12, pp. 109, 2001.

[4] J. Tang and J. Tian, "Application of AHP in the evaluation system on teaching laboratories of fundamental courses,” Research and Exploration in Laboratory , Vol. 25, No. 3, pp. 282, 2006.

[5] Q. F. Geng, "Research on the selection of the supply chain cooperators based on the AHP-Fuzzy evaluation," Value Engineering, Vol. 10, pp. 39, 2005.

[6] H. Q. Zhang and Z. Q. Li, “The application of AHP to network plan evaluation, " Construction and Design for Project, Vol. 10, pp. 84, 2004. 